\title{
THE WAY FORWARD IN DEVELOPING AND INTEGRATING FERRY-BOX TECHNOLOGIES
}

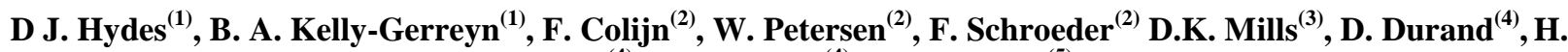 \\ Wehde $^{(4)}$, K. Sørensen ${ }^{(4)}$, G. Morrison ${ }^{(5)}$ \\ ${ }^{(1)}$ National Oceanography Centre, Waterfront Campus, European Way, Southampton SO14 3ZH, United Kingdom, \\ Email: djh@noc.soton.ac.uk; bag@noc.soton.ac.uk \\ ${ }^{(2)}$ HZG (Helmholtz-Zentrum Geesthacht) (formerly GKSS (Gesellschaft zur Förderung der Kernenergie in Schiffbau \\ und Schiffstechnik) Institute for Coastal Research/Research Centre), D-21502 Geesthacht, Germany, \\ Email: franciscus.colijn@gkss.de; wilhelm.petersen@gkss.de; friedhelm.schroeder@gkss.de \\ (3) CEFAS (Centre for Environment, Fisheries \& Aquaculture Science), Lowestoft Suffolk NR33 OHT, United Kingdom \\ Email: david.mills@cefas.co.uk \\ (4) NIVA (Norwegian Institute for Water Research), Thormфhlensgate 53 D, N-5006 Bergen, Norway \\ Email: dominique.durand@niva.no; henning.wehde@niva.no; kai.sorensen@niva.no \\ (5) International SeaKeepers Society, 4101 Ravenswood Rd \# 128, Fort Lauderdale, FL 33312-5301 USA, \\ Email: morrison@SeaKeepers.org
}

\section{EXECUTIVE SUMMARY}

Co-operation between scientists and the shipping industry offers great potential over the next decade for the expansion of marine observations. Work with so called "Ferry-boxes" has made large advances in the last ten years focusing on shelf seas. We expect this work to expand globally and link into other operations more focused on the open sea and sub surface measurements. This may be through the more organised alliances currently being considered by SCOR-OceanScope (Scientific Committee on Oceanic Research-Working Group) (www.scor-int.org/Working_Groups/wg133.htm). It would be timely to consider bringing a global pilot project into being as part of Coastal GOOS (Global Ocean Observing System). The term "Ferry-box" signifies (1) the use of a ferry (or other commercial ships) for data collection, (2) boxes of autonomous sensing equipment installed on the ship, and (3) the ability of the data to provide boundary conditions for numerical models in a delimited or boxed region. The EU (European) project FerryBox (2002-2005) demonstrated that it is possible to provide surface ocean data from commercial ships in a highly cost effective manner over a wide range of temporal and spatial scales. The concept is now in use globally, particularly in Europe, Australia, Japan, Korea and the USA.

The focus of Ferry-box activity has been on improving the understanding of biogeochemical and biological processes in shelf seas. The Ferry-box concept has considerable potential for expansion to include the study of inputs from the world's major riverine discharges and more generally to provide operational observations over coastal zones, shelf seas and the open ocean. This potential for expansion should be strongly encouraged. Immediate requirements are for improvements in the reliability and robustness of existing systems, particularly for measuring nutrients, $\mathrm{pCO}_{2}$ and $\mathrm{pH}$ as well as extension to already trialled equipment such as Acoustic Doppler Current Profilers (ADCP) and flow cytometers.

In Europe, the output from Ferry-box systems is now seen as an important part of a pan European observational system for integration into data networks (e.g. EMODNET - European Marine Observation and Data Network) for use in marine management. Practically, this integration is beginning to evolve through initiatives such as the EU Framework 7 projects MyOcean (2009-2012) and EMECO (European Marine Ecosystem Observatory), which will link to national systems such as COSYNA (Coastal Observation System for Northern and Arctic Seas). The use of Ferry-boxes within these observational systems and networks will enhance the provision of much needed data to enable for example more reliable assessments of the ocean's ability to sequester $\mathrm{CO}_{2}$, and the OSPAR (Oslo/Paris convention (for the Protection of the Marine Environment of the NorthEast Atlantic) Common Procedure looking at eutrophication.

\section{BACKGROUND}

A central goal to understanding the response of the oceans to environmental change is access to relevant observations. Such observations must have sufficient spatial coverage and temporal resolution to give a true view of state and change in the oceans. However, until recently, a major obstacle to achieving this goal has been the lack of monitoring systems that provide reliable, regular, on-line data. To overcome this problem developments have been pursued in measurement technologies, data logging and ship-shore communications. It is now possible for scientists and governmental (environmental) agencies to work with commercial shipping companies to collect this much- 
needed data, autonomously in a cost effective manner. In this paper, we briefly describe what has been achieved and address the potential future contribution to enhancements in marine observatories.

The Ferry-box concept has developed as a partnership between scientists and the companies operating ferries in waters around the world. The potential for data coverage by ferries is large. Eight hundred (800) operate in European seas. In Europe, some 30 ships are involved in this type of work (www.ferrybox.org) and systems have also been in operation for some time in Japan (Harashima \& Kunugi, 2000) in the USA (Ensign \& Pearl, 2006; Paerl et al., 2005) and Australia. A co-ordinated data collection operation is that run by the International Sea Keepers Society (www.seakeepers.org). A map of the routes currently carrying Ferry-boxes on the North West European shelf is shown in Fig 1. Progress has been considerable since it was reviewed by Miller et al., (2002).

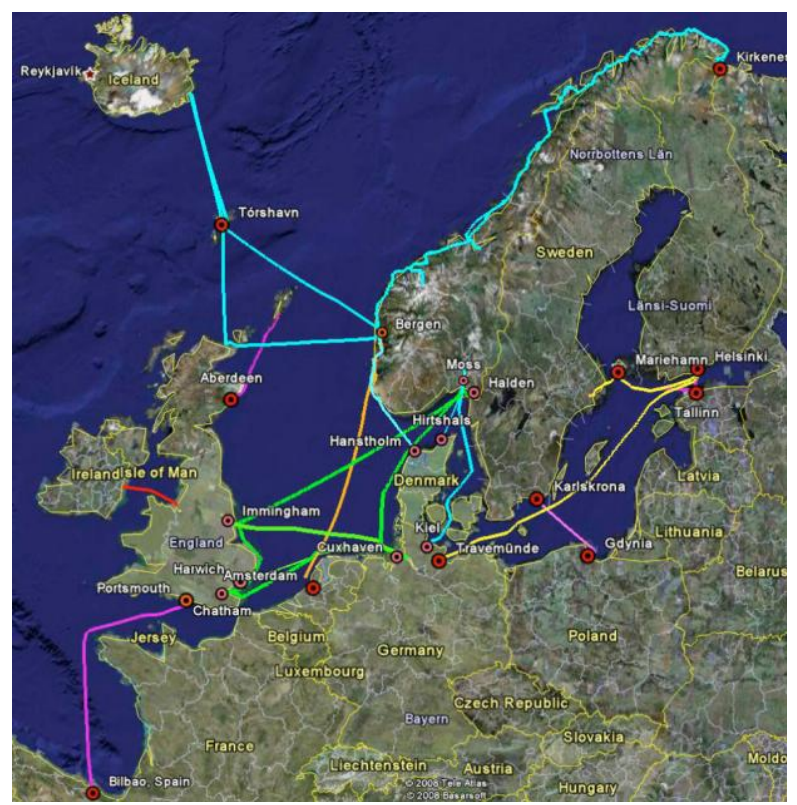

Figure 1. Map of the North West European shelf sea area showing the routes of Ferry-box systems in operation in March 2009.

The EU FP5 project "FerryBox" (2002-2005) demonstrated the utility of the concept (Petersen et al., 2005). The FerryBox project used of four "core" sensors for temperature, salinity, chlorophyllfluorescence, and turbidity by all the partners (Petersen et al., 2007). Individual groups tested a wider range of sensors and deployed towed instruments such as the Continuous Plankton Recorder (CPR). Conductivity sensors for surface water salinity provided scientifically interesting data on water transport when collected as part of a consistent time series (KellyGerreyn et al., 2006), demonstrating the importance of salinity for coastal monitoring programmes. Where only surface waters were sampled (as was the majority case in the FerryBox project), it was shown that Ferryboxes are highly complementary to other data from fixed buoys, research vessels and modelling (Petersen et al., 2008). In addition profiling instruments such as ADCPs (Acoustic Doppler Current Profilers) can enable observations through the water column (Flagg et al., 2006; Buijsman \& Ridderinkhof, 2007) alongside more traditional XBTs (expendable bathy thermographs) for profiling the water column for temperature (e.g. Fuda et al., 2000). Biological information can be gained acoustically (i.e. Griffiths \& Diaz, 1996) and with towed instruments such as with the CPR (Continuous Plankton Recorder; see below).

The International SeaKeepers Society (ISKS) in the USA has developed a variant on the Ferry-box theme. Over the last 10 years with the international philanthropic support, the organization has developed and deployed the patented Seakeeper 1000 monitoring systems on close to 90 platforms. The Seakeeper 1000 units monitor meteorological and surface physical oceanographic parameters They contains expansion space for the deployment of new sensors and technologies as they become available.

Many of the systems have been developed to support the requirements for both scientific and marine management data. For example, Ferry-boxes are used by both the Finnish Environment Institute (the AlgaLine system (www.fimr.fi/en/tietoa/algaline_seuranta/en_GB/) and the Norwegian Institute of Water Research (NIVA, the NorHAB (Norwegian Harmful Algal Bloom) system www.ferrybox.no) to improve surveillance of the harmful and nuisance blooms of algae that plague the Baltic (Backer et al., 2008) and the North Sea.

Globally a major advance has been the monitoring of air-sea fluxes of carbon dioxide $\left(\mathrm{CO}_{2}\right)$ (e.g. Schuster and Watson, 2007). This has been coordinated by through the International Ocean Carbon Coordination Project (IOCCP www.ioccp.org). It is important that this work is continued and expanded in shelf seas, whose contribution to the carbon budget is particularly difficult to predict from existing models. Coastal carbon issues are important in the international (UN) agenda because it is felt that management and policy decisions are more easily made at the local and regional level. The Ferry-box/VOS (Volunteer Observing Ship) approach outlined here is probably the only way to provide the needed monitoring coverage of both carbon import and export in shelf seas and 
acidification in the coastal zone in a cost effective manner.

Currently Ferry-boxes are being integrated into some European marine management system as described below. Looking to the future a SCOR (Scientific Committee on Oceanic Research) working group called 'OceanScope' started work in 2009 to look at the enhancement of the partnership between the ocean observing community and the shipping industry. The aims of OceanScope are to identify: -

1. Needed observations with respect to parameters and location

2. Priory routes for sustained ocean observation

3. Available technologies for measurement and communication

4. Priory instrument needs to meet future mission requirements

5. Data management needs (handling, and archival) and issues of data ownership

6. Potential problems related to national and international jurisdictions

7. An organisational and funding structure to sustain a long-term integrated international merchant marine based observation program, linked closely to existing ocean observing systems and programs - an Ocean Space Centre - OPC (Ocean Prediction Center).

OceanScope will consider the global integration of existing system such as the European FerryBox activities and the IOCCP $\mathrm{CO}_{2}$-VOSs. It sees its focus being on sea surface and water column properties making it distinct from existing data gathering. But, how an OPC would develop along side existing activities such as JCOMM (Joint Technical Commission for Oceanography and Marine Meteorology) needs to be defined.

\section{INTEGRATION OF FERRY-BOXES INTO OBSERVING SYSTEM NETWORKS AND THE MARINE MONITORING CYCLE}

\subsection{Marine monitoring cycle exemplified for eutrophication problems}

The marine monitoring cycle is the process of the provision of information by observationalists to managers and policy makers and the feedback to the observationalists of further needs for measurements. Eutrophication is a globally important environmental problem for which there is a clear need for improved monitoring. We need to better understand the process itself and how effective remedial actions are in practice. In Europe, schemes for monitoring and assessment of eutrophication have been put in place, so that individual countries can comply with international conventions (e.g. OSPAR and HELCOM (Helsinki Commission)) and European Directives (e.g. Nitrates Directive, Water Framework Directive). OSPAR defines eutrophication as the enrichment of waters by nutrients causing an accelerated growth of algae and higher forms of plant life to produce an undesirable disturbance to the balance of organisms present in the water and to the quality of the water concerned. (OSPAR, 2003) To meet OSPAR needs for detection and diagnosis of eutrophication, monitoring is required to be carried out for a range of assessment parameters. These include the level of over-winter nutrients, NP ratio, growing season chlorophyll concentration, abundance of phytoplankton indicator species, shifts in phytoplankton species composition and levels of dissolved oxygen concentration. Multi-year trends in ambient nutrient concentration and riverine nutrient inputs are also taken into account in determining the outcome to an assessment. The Ferry-box approach can provide a cost effective path to meeting many of these requirements.

Traditional monitoring of coastal and offshore waters has relied upon intermittent sampling using survey vessels. This approach is costly and leads to under sampling in space and time and consequently aliasing and large uncertainties in the accuracy of data used for assessments. In Europe, these uncertainties are a serious concern when the outcome to an assessment may be subject to legal scrutiny with the threat of punitive fines and costly remediation. To reduce the expenses associated with appropriate sampling, the use of Ferry-boxes is now coming on stream, together with fixed point monitoring from buoys. As a result there has been, for some countries, a step-wise increase in the size of the database used to assess eutrophication leading to greater accuracy and robustness in assessments, thus improving reliability. After data analysis, the information is returned to the managing environmental agencies for assessment and then to policy makers.

\subsection{Examples of integrated monitoring using Ferry-boxes}

\subsubsection{A European wide monitoring strategy: EMODNET}

The value of the integrated approach required by OSPAR and other authorities is beginning to be recognised. Concerted efforts are underway to expand the approach to ensure that the benefits that can be achieved are fully realised. An objective of EU maritime policy is to overcome the problem that data are available from many sources but assembling them for particular applications takes considerable effort. The European Commission has established EMODNET (European Marine Observation and Data 
Network) to open up opportunities to improve the efficiency of marine observation and management. The vision is for integrated data communications, management and delivery systems, supported by useroriented toolkits.

\subsubsection{European observatories: The European Marine Ecosystem Observatory EMECO}

The building blocks of EMECO (European Marine Ecosystem Observatory) are national marine monitoring programmes, regional observatories (e.g. COSYNA Coastal Observation System for Northern and Arctic Seas), Ferry-box routes, buoy networks and satellite observations. EMECO will provide integrated information products via web interfaces that are designed to provide the evidence base to underpin assessments of eutrophication and future ecosystem health. EMECO will contribute in meeting the challenges posed by the new European Marine Strategy Framework Directive (MSFD) that requires assessments to consider a particular problem in the light of the whole eco-system. The required observations need to cross national boundaries and consider all factors from marine physics to fish ecology over wide time and space scales. The data delivery from EMECO is planned to be on a broader scale than that prescribed in the OSPAR Common Procedure.

\subsubsection{An example for local observatories: The role of Ferry-boxes in COSYNA}

Ferry-box observations can be linked with other observational mechanisms and models to obtain a wide spatial and temporal coverage. One example of integrated monitoring in which Ferry-boxes play a prominent role is the German COSYNA system in the German Bight of the North Sea (http://www.cosyna.de). The system under construction consists of the following observational components (see Fig. 2): Three Ferry-box routes, complemented by two measuring stations on poles in the Wadden Sea, two coastal X-band radar stations and two autonomous riverside stations. These components are operated by the GKSS Research Centre (Institute for Coastal Research, GKSS (Gesellschaft zur Förderung der Kernenergie in Schiffbau und Schiffstechnik) Research Centre (HZG (Helmholtz-Zentrum Geesthacht ) (formerly GKSS)) and are complemented by stations operated by other German institutions (BSH (Bundesamt für Seeschifffahrt und Hydrographie/Federal Maritime and Hydrographic Agency), AWI (Alfred-Wegener-Institut für Polar- und Meeresforschung/Institute for Polar and Marine Research in the Helmholtz Association) and University of Oldenburg). Data from all these systems are qualitycontrolled by the project partners and stored in a database with web access (http://www.coastlab.org). Near-real time COSYNA data will be assimilated into models in order to provide reliable now-casts and short-term forecasts. The systematic coupling of observations and forecasts will be the basis for scientific applications that support different end users from science and political bodies to help make environmental management decisions.

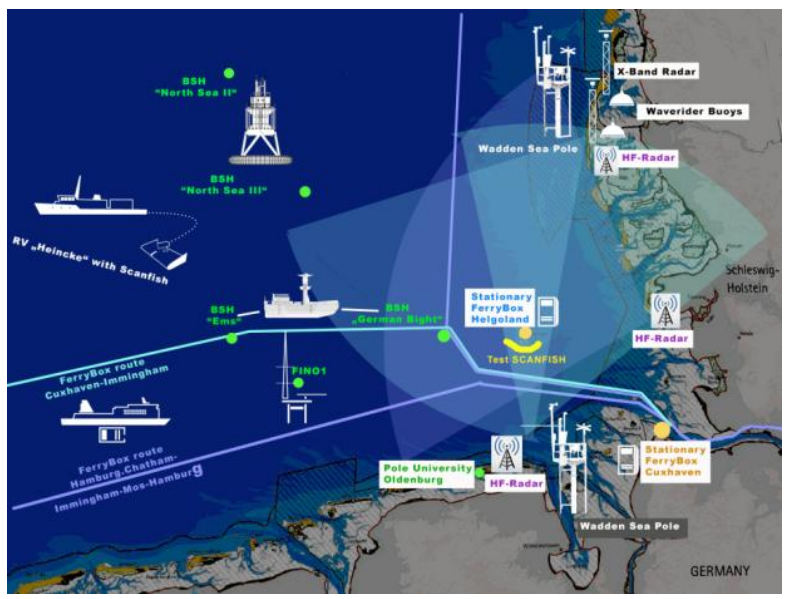

Figure 2. Map of the southern bight of the North Sea indicating the disposition of the range of data collection platforms used by the COSYNA project

A key contribution to the data sets comes from the Ferry-boxes because of the near continuous records they provide. In addition, the Ferry-boxes not only measure a wider range of parameters $\left(\mathrm{S}, \mathrm{T}, \mathrm{O}_{2}, \mathrm{CO}_{2}\right.$, $\mathrm{pH}$, turbidity, chlorophyll-fluorescence, nutrients, species composition - based on discrete water samples - and algal groups- fluorescence spectra) than is possible from other platforms but also do it more reliability. Although data from Ferry-boxes is onedimensional in space (surface waters along the ship's track), the information can be used synergistically with data from satellites and appropriate transport models, to provide a two-dimensional view (e.g. Petersen et al., 2008).

\section{WHAT WE NEED TO IMPROVE THE CAPACITY OF FERRY-BOXES}

The outcomes of the FerryBox project proved that the concept is robust, and that Ferry-boxes can reliably provide good data. It should be emphasised that a considerable amount of experience and know-how in operating these systems is available on the ad-hoc design and maintenance procedures needed in different areas. Systems need to be set up appropriately for the properties of the water body being sampled. For example - some systems tend to suffer from biological fouling and accumulation of sediment in the measurement chambers can cause problems, as can bubbles in the water supply. It is therefore highly recommended that new groups wanting to set up 
systems consult experienced operators before specifying their own system.

One key requirement in operational observing systems is that maintenance effort must be kept to a minimum. A target for the next 10 years will be to find the best combination of robust sensors that can be cleaned either by the ship's staff or through automated cleaning systems, which themselves need little skilled maintenance. A good example of what is needed and a particular success story in the last 4 years has been the oxygen optode sensor, which offers simplicity, reliability and good precision (Tengberg et al., 2006; Hydes et al., 2009). It exemplifies the kind of development that is needed for an instrument to become a standard part of many Ferry-boxes.

A constant dialogue with equipment manufacturers is essential to ensure they keep in mind where and how the equipment they are building it is going to be used (e.g. working in $40{ }^{\circ} \mathrm{C}$ temperatures in the ship's engine room) so that it is really "fit for purpose". Often this can easily be achieved by ergonomic design that takes into account the use in non-laboratory conditions. Alliance for Coastal Technologies (ACT; www.act$\underline{\text { us.info) }}$ has done much to improve the dialogue between users and manufacturers and it is an example that could be followed more widely.

For example, sensor systems are needed to measure $\mathrm{CO}_{2}$ related parameters to study the relationship between anthropogenic $\mathrm{CO}_{2}$ release and ocean uptake, and consequent ocean acidification (Borges et al.; Feeley et al and Monteiro et al., 2010). Instruments to determine $\mathrm{pCO}_{2}$ are available. Equilibrator-based systems have been successfully used in ship of opportunity systems. However, they have high maintenance overheads and considerable effort is needed in the measurement and calculation of $\mathrm{pCO}_{2}$ values (Pierrot et al., 2009). Simpler systems based on gas transfers across an in-situ membrane are being developed and offer the potential to provide high quality data at a lower overhead making it easier to install them on a wider range of vessels (see de Byrne et al., 2010). Particularly when used in conjunction with measurements of total dissolved gas pressure (McNeil et al., 1995), membrane systems offer the potential for improved and more robust measurements in the near future. Work is under way at the National Oceanography Centre, Southampton and at GKSS to manufacture reliable high precision $( \pm 0.001)$ instruments for the determination of $\mathrm{pH}$ following on earlier work that proved the concept of using colorimetry (e.g. Friis et al., 2004). Equipment for $\mathrm{pH}$ is expected to be manufactured in the near future. Other research is carried out at GKSS to measure total alkalinity and total dissolved inorganic carbon autonomously.
Developments for the measurement of other climatically active gasses e.g. nitrous oxide and methane should be encouraged. For work in potentially more polluted coastal environments rapid systems for assessing organic pollutants are needed. A Ferry-box type system for monitoring persistent organic pollutants has been trialled in Japan (Masayuki et al., 2006).

Ship-mounted ADCP is also of great potential within the Ferry-box concept. Several low-speed cargo ships are equipped with ADCPs that provide measurement of current speed and direction in the water column beneath the ship. This monitoring technique is efficient, as it requires a very limited maintenance effort. However, progress in data analysis is needed if these systems are to be used on ferries that commonly cruise at a speed of 20 knots. New approaches based on artificial intelligence are being investigated. This effort has to be sustained, as high frequency observations of the vertical current patterns along transect would be of tremendous importance to assess the coupling between physical and biochemical processes.

Sensors for more biologically relevant measurements are needed. One of the first systems used regularly on ships of opportunity was the Continuous Plankton Recorder CPR (see Reid et al., 2010). Using a concept developed in the 1930s, zooplankton are collected on silk screens and are sent ashore for taxonomic analysis some months later. More rapid assessment of zooplankton abundance is needed to understand plankton bloom dynamics in systems like EMECO. Often, it is only necessary to assess zooplankton abundance; accurate taxonomic analysis can be provided at a later stage. Rapid data assessment can be performed in "flow cams" as part of an inboard Ferrybox system. Promising systems that use video cameras with sophisticated pattern recognition software are under development (Blaschko et., 2005; Tang et al., 1998). Acoustic sensors (such as the ASL (ASL Environmental Sciences Inc.) Multiple - Frequency Acoustic Water Column Profiler) could be used either attached to the hull or on towed bodies. Such measurements would also serve to complement and reduce the aliasing inherent in the taxonomically robust CPR measurements, which are traditionally only made on a monthly basis.

Other sensor systems that are now in the experimental stage use modern bioengineering/genetic processes to automatically identify single phytoplankton species or - groups ("Geneprobe"). These may be especially useful for the specific detection of harmful algae (Metfies et al., 2006; Scholin et al 2008; Scholin, 2009). Such systems have already been packaged for use on moored systems making them robust enough for autonomous use on ships. Simple measurements of chlorophyll-fluorescence provide a crude indication of 
phytoplankton abundance and these can be extended using multiple wavelength techniques to provide indication of the presence of different algal groups and dissolved organic matter (Blue Green Algae Phycocyanin/Phycoerythrin and CDOM (Colored Dissolved Organic Matter)). Other systems such as flow cytometers have been trialled and offer the potential for providing extra key biological information at a species level (www.cytobuoy.com).

Some chemical and biological determinations will continue to require water sampling and water samples are also crucial for calibration and/or validation of autonomous and online measurement. Some Ferry-box systems have done this using simple water samplers, such as the Teledyne-ISCO sampler (www.isco.com). It is recommended that some effort be put into the development of water samplers capable of collecting and preserving tens of samples. A second requirement is for automated filtering with preservation of the filtrate. Some work is underway to produce robotic sampling devices capable of operating autonomously to filter samples and place the filtered material into a low temperature freezer.

The feedback between the constant observation that can be made from VOS systems and satellite observations should not be overlooked. For example, the NIVA Ferry-boxes make in-air measurements of solar radiation, aerosol properties, and water-leaving radiance. These have proven of significant importance for assessing light conditions and aerosol properties and variability in coastal regions.

\section{FERRY-BOXES IN CONTEXT OF OCEANOBS'09}

OceanObs'09 is providing a forum for exploring how Ferry-boxes might best be used in the future and how their use can be encouraged globally, whether it is for research on global problems such as ocean uptake of $\mathrm{CO}_{2}$ and acidification, or more local problems such as eutrophication and other pollutants.

Ferry-boxes can make important contributions to the development of a worldwide system for observing the coastal and open ocean: In the context of developing countries, the Ferry-box approach is particularly important because it is highly cost effective (Petersen et al., 2007). Key to the success of GOOS is its practical wing JCOMMOPS (Joint WMO-IOC Technical Commission for Oceanography and Marine Meteorology (JCOMM) Observing Platform Support Centre). The OceanObs'09 Conference will provide the opportunity to discuss how Ferry-box operations might be coordinated globally to provide input to a Coastal GOOS system (Malone et al., 2010). For example, SeaKeepers are developing software to actively share data collected in areas of specific interest in which data from a cruise ship transiting a particular area will be automatically brought to the attention of designated individuals and made available to them. Other ideas that might be discussed and will be considered by OceanScope are for example the work of the Open Geospatial Consortium (OGC; www.opengeospatial.org), which is playing an important role in trying to standardise data formats and interoperability. Similarly along these lines, it could be instructive to compare the role played by NOAA's National Data Buoy Center in collating and standardizing data on a global scale with the similar role performed by JCOMMOPS.

It is crucial that all data are quality controlled, maintained, disseminated and archived following welldescribed methods. The EU FerryBox project made progress by defining meta-data protocols. One important piece of work developing out of Ocean Obs'09 will be how data managers can prepare and manage the potential increase in data that will be available to them the next few years. Web technologies such as the "semantic web" could play an important role in terms of accessing collected data but also in communications between scientists and their remote instruments.

\section{REFERENCES}

1. Backer, H. and Leppänen, J-M., (2008). The HELCOM system of a vision, strategic goals and ecological objectives: implementing an ecosystem approach to the management of human activities in the Baltic Sea Aquatic conservation: marine and freshwater ecosystems 18:321-334.

2. Belbeoch, M. \& Co-Authors (2010). "The JCOMM In Situ Observing Platform Support Centre: A Decade of Progress and Remaining Challenges" in these proceedings (Vol. 2), doi:10.5270/OceanObs09.cwp.04

3. Blaschko, M.B., and Co-Authors (2005). Automatic In Situ Identification of Plankton Proceedings of the Seventh IEEE Workshops on Application of Computer Vision (WACV/MOTION'05), pp 79 - 86 (01 2005)

4. Borges, A. \& Co-Authors (2010). "A Global Sea Surface Carbon Observing System: Inorganic and Organic Carbon Dynamics in Coastal Oceans" in these proceedings (Vol. 2), doi:10.5270/OceanObs09.cwp.07

5. Buijsman, M.C. and H. Ridderinkhof, (2007). Long-term ferry-ADCP observations of tidal currents in the Marsdiep inlet. J. Sea Res. 57, 237-256

6. Byrne, R. \& Co-Authors (2010). "Sensors and Systems for In Situ Observations of Marine Carbon Dioxide System Variables" in these proceedings (Vol. 2), doi:10.5270/OceanObs09.cwp.13

7. COSYNA, (2009) www.cosyna.de

8. Davis, C. S., S. M. Gallager, M. S. Berman, L. R. Haury, and J. R. Strickler, (1992a). The Video Plankton 
Recorder (VPR): Design and initial results. Arch. Hydrobiol. Beih. 36: 67-81

\section{EMECO, (2009). www.cefas.defra.gov.uk}

10. Ensign, S.H. and HW. Paerl. (2006). Developing an unattended estuarine nutrient monitoring program using ferries as data-collecting platforms. Limnology and Oceanography Methods 4:70-76

11. Feely, R. \& Co-Authors (2010). "An International Observational Network for Ocean Acidification" in these proceedings (Vol. 2), doi:10.5270/OceanObs09.cwp.29

12. Flagg, C. N., M. Dunn, D.-P. Wang, H. T. Rossby, and R. L. Benway, (2006), A study of the currents of the outer shelf and upper slope from a decade of shipboard ADCP observations in the Middle Atlantic Bight, $J$. Geophys. Res., 111, C06003, doi:10.1029/2005JC003116.

13. Friis, K., K., Körtzinger, A., Wallace, D. W.R., (2004). Spectrophotometric $\mathrm{pH}$ measurement in the ocean: Requirements, design, and testing of an autonomous charge-coupled device detector system. Limnology and Oceanography Methods 2, 126-136.

14. Fuda, J.; Millot, C.; Taupierletage, I.; Send, U.; Bocognano, J., (2000). XBT monitoring of a meridian section across the western Mediterranean Sea Deep Sea Research (1) 47, 2191-2218.

15. Griffiths G.1; Diaz J.I., (1996) Comparison of acoustic backscatter measurements from a ship-mounted Acoustic Doppler Current Profiler and an EK500 scientific echo-sounder. ICES Journal of Marine Science, 53, 487-491

16. Harashima, A. and M. Kunugi, (2000). Comprehensive Report on Marine Environmental Monitoring and Related Studies Using Ferry Boats. CGER-Report, National institute for Environmental Studies, Environmental Agency of Japan, CGER-M007-2000, ISSN 1341-4356.

17. Hydes, D.J., Hartman, M. C., Kaiser, J., Campbell, J.M., (2009). Measurement of dissolved oxygen using optodes in a FerryBox system. Estuarine and Coastal Shelf Research, 83, 485-490.

18. Kelly-Gerreyn, B.A., Hydes, D.J., Jegou, A.M., Lazure, P., Fernand, L.J., Puillat, I. and Garcia-Soto, C., (200)6. Low salinity intrusions in the western English Channel. Continental Shelf Research, 26, 1241-1257.

19. Malone, T. \& Co-Authors (2010). "Building a Global System of Systems for the Coastal Ocean: A Strategic Action Plan for Implementing the Coastal Module of GOOS" in these proceedings (Vol. 2), doi:10.5270/OceanObs09.cwp.59.

20. Masayuki, K., Fujimori, K., Nakano, T., (2006). Development of Observation Systems for Global-Scale Marine Pollution with Persistent Organic Pollutants Deployed on Voluntary Observation Ships Bunseki Kagaku, 55, 835-845.
21. McNeil, C. L., B. D. Johnson, and D. M. Farmer, (1995). In situ measurement of dissolved nitrogen and oxygen in the ocean. Deep-Sea Res., 42A, 819-826.

22. Metfies, K., Tobe, K., Scholin, C., and Medlin, L. K. (2006). Laboratory and field applications of ribosomal RNA probes to aid the detection and monitoring of harmful algae, in Ecology of Harmful Algae, edited by: Graneli, E., and Turner, J. T., Springer Verlag, Berlin, 311-325, 2006.

23. Miller, C.B. (ed.) (2002). Report of the PICES 2002 Volunteer Observing Ship Workshop, PICES Scientific Report No.21, 2002.

24. Monteiro, P. \& Co-Authors (2010). "A Global Sea Surface Carbon Observing System: Assessment of Changing Sea Surface CO2 and Air-Sea CO2 Fluxes" in these proceedings (Vol. 2), doi:10.5270/OceanObs09.cwp.64

25. OSPAR Commission, (2003). The OSPAR Integrated Report 2003 on the Eutrophication Status of the OSPAR Maritime Area based upon the first application of the Comprehensive Procedure. Includes "baseline/assessment levels used by Contracting Parties and monitoring data (MMC 2003/2/4; OSPAR Publication 2003: ISBN: 1-904426-25-5).

26. Paerl, H.W., L.M. Valdes, J.E, Adolf, B.M. Peierls and L.W. Harding Jr., (2005). Anthropogenic and climatic influences on the eutrophication of large estuarine ecosystems. Limnology and Oceanography.51: 448-462

27. Petersen et al., (2007). FerryBox: From On-line Oceanographic Observations to Environmental Information. Petersen, W., Colijn, F., Hydes, D., Schroeder, F., Editors. EuroGOOS Publication No. 25. EuroGOOS Office, SHMI, 60176 Norkoepping, Sweden ISBN 978-91097828-4-4.

28. Petersen, W., F. Colijn, J. Elliot, M.J. Howarth, D.J. Hydes, S. Kaitala, H. Kontoyiannis, A. Lavín, I. Lips, K.D. Pfeiffer, R. Proctor, H. Ridderinkhof and K. Sørensen, (2005). European FerryBox Project: From Online Oceanographic Measurements to Environmental Information. In: Dahlin, H. et al. (eds) European Operational Oceanography: Present and Future. Proceedings of the 4th EuroGOOS Conference, Brest (France); ISBN 92-894-9722-2.

29. Petersen, W., Wehde, H., Krasemann, H., Colijn, F., Schroeder, F., (2008). FerryBox and MERIS Assessment of coastal and shelf sea ecosystems by combining in situ and remotely sensed data. Estuarine, Coastal and Shelf Science 77, 296-307.

30. Pierrot, D., C. Neill, K. Sullivan, R. Castle, R. Wanninkhof, H. Lüger, T. Johannessen, A. Olsen, R. A. Feely, C. E. Cosca, (2009) Deep Sea Research Part II: Topical Studies in Oceanography, Available online 13 December 2008

31. Reid, P. \& Co-Authors (2010). "A Global Continuous Plankton Recorder Programme" in these proceedings (Vol. 2), doi:10.5270/OceanObs09.cwp.73. 
32. Scholin, C., (2009). What are "ecogenomic sensors"? A review and thoughts for the future, Ocean Sci. Discuss., 6, 191-213, 2009, http://www.ocean-sci-discuss.net/6/191/2009/.

33. Scholin, C. A., Doucette, G. J. and Cembella, A. D., (2008). Prospects for developing automated systems for in situ detection of harmful algae and their toxins, in Real-Time Coastal Observing Systems for Ecosystem Dynamics and Harmful Algal Blooms, edited by: Babin, M., Roesler, C. S., and Cullen, J. J., UNESCO Publishing, Paris, France.

34. Schuster, U. and Watson, A.J., (2007). A variable and decreasing sink for atmospheric $\mathrm{CO} 2$ in the North Atlantic, J. Geophys. Res., 112, C11006, doi:10.1029/2006JC003941

35. Tang, X. Stewart W. K, Vincent, L Huang, H., Marra, M., Gallager S M., Davis, C S., (1998). Automatic Plankton Image Recognition, Artificial Intelligence Review 12: 177-199.

36. Tengberg, A., Hovdenes, J., Andersson, J.H., Brocande, O., Diaz, R., Hebert, D., Arnerich, T., Huber, C., Körtzinger, A., Khripounoff, A., Rey, F., Rönning, C., Sommer, S., Stangelmayer, A., (2006). Evaluation of a Life Time based Optode to measure Oxygen in Aquatic Systems. Limnology and Oceanography, Methods 4, 717. 